\title{
PENDEKATAN THERAPLAY UNTUK MENINGKATKAN PENGETAHUAN DAN KETERAMPILAN BERMAIN DENGAN ANAK PENYANDANG KANKER
}

\author{
Dewi Kumalasari ${ }^{1}$, Rina Rahmatika ${ }^{2}$, Titi Sahidah Fitriana ${ }^{3}$ \\ Fakultas Psikologi, Universitas YARSI, Jakarta \\ *E-mail: dewi.kumalasari@yarsi.ac.id
}

\begin{abstract}
Sekolah-Ku is a program that aims to provide opportunities for children with cancer to learn for those who want to keep in school materials so that if they have completed cancer treatment / treatment they can immediately catch up school materials. The purpose of this intervention is to improve the knowledge and skills of the Sekolah-Ku teachers in applying theraplay principles in learning and interaction with cancer students. To find out the effects of the training, knowledge of the principles and applications of Theraplay will be carried out before and after training. Evaluation of the effect of training is done by comparing the knowledge of principles and applications of Theraplay before and after training. There was a difference in knowledge of significant differences in Theraplay knowledge $(Z=-3,236, p<0.05)$ in training participants before and after training activities. The follow-up results show that behaviors that indicate dimensions in theraplay have emerged at $52.78 \%$ to $86.11 \%$. This results indicate that this program is effective improve the knowledge and skills of the Sekolah-Ku teachers in applying theraplay principles in learning and interaction with cancer students.
\end{abstract}

Keywords: Cancer; Sekolah-Ku; Teacher; Theraplay

\begin{abstract}
Abstrak
Sekolah-ku' merupakan suatu program yang bertujuan memberikan kesempatan anakanak penyandang kanker untuk belajar bagi yang ingin mengikuti pelajaran sekolahnya sehingga bila mereka telah menyelesaikan pengobatan/ perawatan penyakit kanker dapat segera mengikuti pelajaran kembali. Tujuan dari intervensi ini adalah meningkatkan pengetahuan dan keterampilan para guru 'Sekolah-ku' dalam menerapkan prinsip-prinsip theraplay dalam kegiatan pembelajaran dan interaksi dengan anak didik penderita kanker. Untuk mengetahui efek dari pelatihan, akan dilakukan pengetahuan prinsip dan aplikasi Theraplay sebelum dan sesudah pelatihan. Evaluasi dari efek pelatihan dilakukan dengan membandingkan pengetahuan prinsip dan aplikasi Theraplay sebelum dan sesudah pelatihan. Terdapat perbedaan pengetahuan perbedaan yang signifikan dalam pengetahuan mengenai theraplay $(Z=-3.236$, $p<0.05)$ pada peserta pelatihan sebelum dan sesudah kegiatan pelatihan. Dari hasil follow up tampak bahwa perilaku yang mengindikasikan dimensi-dimensi dalam theraplay telah muncul sebesar 52,78\% hingga 86,11\%. Hasil ini menandakan bahwa program ini efektif dalam meningkatkan pengetahuan dan keterampilan para guru 'Sekolah-ku' dalam menerapkan prinsip-prinsip theraplay dalam kegiatan pembelajaran dan interaksi dengan anak didik penderita kanker.
\end{abstract}

Kata Kunci : Kanker; Guru; Sekolah-Ku; Theraplay

\section{PENDAHULUAN}

Di Indonesia, diperkirakan setiap tahun ada 4.100 kasus baru kanker pada anak (Tehuteru, 2015). RS Dharmais mencatat terdapat peningkatan jumlah pasien anak penderita kanker setiap tahunnya sejak 2006 hingga saat ini. Berbeda dengan kanker pada individu dewasa, penyakit kanker pada anak tidak dapat dicegah. Namun demikian, kanker pada dasarnya dapat diobati dan 
dapat disembuhkan bila dijumpai pada stadium awal. Hal ini membuat pengobatan kanker sedini mungkin menjadi penting untuk dilakukan.

Pada umumnya, pengobatan kanker membutuhkan waktu yang tidak sebentar. Lamanya pengobatan membuat anak-anak penderita kanker dan/ atau penyakit kronis yang sedang dalam perawatan, baik rawat jalan maupun rawat inap, menghentikan sekolahnya (putus sekolah) sehingga tidak ada aktivitas sama sekali (ykaki.or.id). Hal inilah yang melatarbelakangi program 'Sekolah-ku' yang digagas oleh Yayasan Kasih Anak Kanker Indonesia (YKAKI). YKAKI lahir pada tanggal 1 November 2006 dengan visi bahwa setiap anak Indonesia yang menderita kanker berhak mendapat pengobatan serta perawatan yang sebaik-baiknya, juga hak belajar maupun hak bermain walaupun dalam keadaan sakit (ykaki.or.id).

Dilansir dari ykaki.or.id, tujuan dari program 'Sekolah-ku' adalah untuk memberikan kesempatan anak-anak untuk belajar bagi yang ingin mengikuti pelajaran sekolahnya sehingga bila mereka telah menyelesaikan pengobatan/ perawatan dapat segera mengikuti pelajaran kembali (umumnya terjadi bagi anak-anak SD, SMP dan SMA. Selain itu, bagi anak-anak balita, PAUD/pra-TK dan TK dapat diberikan aktivitas selama perawatan di rumah sakit, agar kelak dapat melanjutkan pendidikan formal SD dan juga dapat membantu menghilangkan kebosanan dan stress yang dialami anak karena lamanya waktu pengobatan.

Dalam kaitannya dengan kondisi stress yang mungkin dialami anak penderita kanker, pembelajaran yang dilakukan perlu melalui aktivitas yang menyenangkan, seperti bermain. Bermain juga membantu anak yang menjalani perawatan medis untuk mengatasi stres dan mengalihkan fikiran mereka dari rasa sakit dan perasaan kesepian (Davidson, Satchi \& Venkatesan, 2017). Salah satu aktivitas bermain yang bersifat terapeutik dan dapat digunakan untuk anak dengan penyakit kronis adalah theraplay (Seymour dalam Rubin, 2017).

Theraplay merupakan terapi bermain yang direktif dan interaktif antara anak dan orang dewasa (Wettig, Franke dan Fjordbak, 2006). theraplay dapat diberikan secara individual maupun kelompok. Sesi-sesi di dalam theraplay bertujuan untuk membangun 4 dimensi yang dianggap sebagai pilar dalam hubungan yang sehat yakni: structure, engagement, nurture dan challenge. Dalam dimensi structure, kegiatan bermain haruslah memberikan rasa aman bagi anak dan memiliki aturan yang jelas, baik bagi anak maupun orang dewasa. Dalam dimensi engagement, Kegiatan yang akan membuat anak dapat terlibat aktif adalah kegiatan yang penuh dengan interaksi, melibatkan aktivitas fisik dan ada kegembiraan yang dirasakan secara bersamasama. Dalam dimensi nurture, Aktivitas mengayomi akan membantu mengatur dan menenangkan anak, menguatkan pesan untuk anak bahwa mereka berharga dan menyediakan berbagai pengalaman dari berbagai respon empatik untuk memenuhi kebutuhan anak akan rasa nyaman. Dalam dimensi challenge, Aktivitas yang menantang akan mengarahkan pada rasa kompeten dan penguasaan keterampilan tertentu.

Dalam konteks pembelajaran, dimensi-dimensi dalam theraplay ini dapat diaplikasikan melalui kegiatan bermain yang dirancang untuk mencapai tujuan pembelajaran tertentu. Melalui dimensi-dimensi tersebut, diharapkan kegiatan bermain sekaligus belajar menjadi aktivitas yang menyenangkan, membangun dan membantu anak meregulasi emosi dengan lebih baik.

Berdasarkan penuturan dari Ibu Ira Soelistyo selaku ketua YKAKI, beberapa tahun yang lalu guru-guru di sekolah-ku telah mendapatkan pelatihan mengenai theraplay. Namun seiring berjalannya waktu, dengan adanya penambahan personil guru, penyegaran (refreshment) mengenai theraplay menjadi dibutuhkan untuk saat ini. Oleh karena itu, kami akan memberikan pelatihan mengenai penerapan prinsip-prinsip theraplay dalam kegiatan pembelajaran untuk guru-guru di sekolah-ku yang bernaung di bawah YKAKI.

\section{METODE}

Metode yang digunakan dalam kegiatan ini adalah berupa pelatihan, dengan modul pelatihan yang disusun berdasarkan sudut pandang teori theraplay dan data kualitatif yang didapatkan dari focus group discussion (FGD) kepada guru-guru. Melalui FGD ini, akan dipetakan pengetahuan dasar para guru mengenai kegiatan bermain. Berdasarkan hasil pemetaan tersebut, akan disusun modul pelatihan dengan pendekatan theraplay yang terdiri dari 2 sesi. Selanjutnya, dilakukan follow up berupa observasi kegiatan bermain yang dilakukan peserta terhadap anak 
penyandang kanker dalam seting alami. Adapun kegiatan pelatihan dilakukan dalam 2 sesi. Berikut adalah perincian kegiatan pada setiap sesi:

Tabel 1. Perincian Sesi Pelatihan

\begin{tabular}{lll}
\hline Sesi & $\begin{array}{l}\text { Tema } \\
\text { Kegiatan }\end{array}$ & Deskripsi Kegiatan \\
\hline \multirow{2}{*}{1} & $\begin{array}{l}\text { Pentingnya } \\
\text { bermain dan } \\
\text { prinsip-prinsip } \\
\text { bermain }\end{array}$ & $\begin{array}{l}\text { Peserta akan diberikan pengetahuan mengenai } \\
\text { pentingnya bermain dan prinsip-prinsip bermain yang } \\
\text { dapat meningkatkan kualitas hidup anak. }\end{array}$ \\
\hline 2 & $\begin{array}{l}\text { Bermain } \\
\text { dengan } \\
\text { pendekatan } \\
\text { theraplay }\end{array}$ & $\begin{array}{l}\text { Pada sesi ini, peserta pelatihan akan diberikan } \\
\text { pengetahuan dan keterampilan mengenai } \\
\text { aktivitas permainan yang sesuai dengan } \\
\text { dimensi-dimensi theraplay, yaitu structure, } \\
\text { engagement, challenge dan nurture. }\end{array}$ \\
\hline
\end{tabular}

\section{Teknik Pengumpulan Data}

Untuk mengetahui efek dari pelatihan, akan dilakukan pengukuran pengetahuan prinsip dan aplikasi theraplay sebelum dan sesudah pelatihan. Berikut adalah pertanyaan yang diajukan dalam pre dan post test:

1. Apa yang Anda ketahui tentang Theraplay?

2. Apa yang Anda ketahui tentang dimensi Structure dalam Theraplay?

3. Apa yang Anda ketahui tentang dimensi Engagement dalam Theraplay?

4. Apa yang Anda ketahui tentang dimensi Nurture dalam Theraplay?

5. Apa yang Anda ketahui tentang dimensi Challenge dalam Theraplay?

6. Jika Anda diminta untuk melakukan kegiatan bermain dengan pendekatan theraplay dengan anak didik Anda, kegiatan apa yang anda lakukan untuk memunculkan ke-empat dimensi theraplay (structure, engagement, nurture, challenge) tersebut? Dan Jelaskan bagaimana cara memunculkan keempatb dimensi tersebut?

Evaluasi dari efek pelatihan dilakukan dengan membandingkan pengetahuan prinsip dan aplikasi theraplay sebelum dan sesudah pelatihan. Selanjutnya, untuk melihat sejauh mana pemahaman peserta tentang materi yang telah diberikan, akan dilakukan follow up dalam bentuk observasi terhadap guru ketika melakukan aktivitas bermain bersama anak. Observasi ini mengacu pada checklist perilaku yang mengindikasikan setiap dimensi dalam theraplay. Berikut adalah checklist perilaku yang dijadikan panduan observasi:

\begin{tabular}{|c|c|}
\hline Dimensi & Perilaku \\
\hline Structure & $\begin{array}{l}\text { - Memberikan informasi tentang cara bermain kepada anak } \\
\text { - Memperhatikan aspek keamanan anak saat bermain } \\
\text { - } \quad \text { Membimbing anak untuk mengikuti permainan }\end{array}$ \\
\hline Engagement & $\begin{array}{l}\text { - Aktivitas bermain memfasilitasi interaksi dengan anak } \\
\text { - Memotivasi anak untuk terlibat dalam permainan } \\
\text { - } \quad \text { Memunculkan rasa gembira, senang dan suasana yang positif }\end{array}$ \\
\hline Nurture & $\begin{array}{l}\text { - Memunculkan rasa nyaman } \\
\text { - Memunculkan rasa berharga pada diri anak } \\
\text { - Menunjukkan sikap empatik pada anak } \\
\end{array}$ \\
\hline Challenge & $\begin{array}{l}\text { - Memfasilitasi aktivitas dengan level kemampuan tertentu } \\
\text { - Menunjukkan dukungan ke anak dalam aktivitas } \\
\text { - Memfasilitasi agar anak mengetahui kemampuan yang mampu ia } \\
\text { lakukan }\end{array}$ \\
\hline
\end{tabular}




\section{Teknik Analisa Data}

Teknik analisa data yang digunakan dalam kegiatan ini adalah Wilcoxon rank test untuk membandingkan mean pengetahuan sebelum pelatihan dan setelah pelatihan. Lebih lanjut, data yang didapatkan dari hasil follow up akan diolah melalui statistik deskriptif.

\section{HASIL DAN PEMBAHASAN}

\section{Pelaksanaan Kegiatan}

Kegiatan ini diikuti oleh 13 orang guru Sekolah-Ku, bertempat di Yayasan Kasih Anak Kanker Indonesia yang berlokasi di Jl. Percetakan Negara XI no. 129, Jakarta Pusat. Sesuai dengan rancangan yang sudah dibuat, kegiatan pertama yang dilakukan adalah Focus Group Discussion (FGD). FGD diselenggarakan pada tanggal 14 Maret 2019. Dalam kegiatan FGD, peserta dibagi dalam 2 kelompok yang dimana dalam setiap kelompok dilaksakan diskusi kelompok terarah yang dipandu oleh tim pengabdian masyarakat. Konten yang digali dalam FGD adalah menegnai pengalaman bermain yang selama ini sudah peserta lakukan dengan anak penderita kanker. Hasil dari FGD ini menjadi bahan dalam penyusunan materi yang akan disampaikan dalam sesi pelatihan.

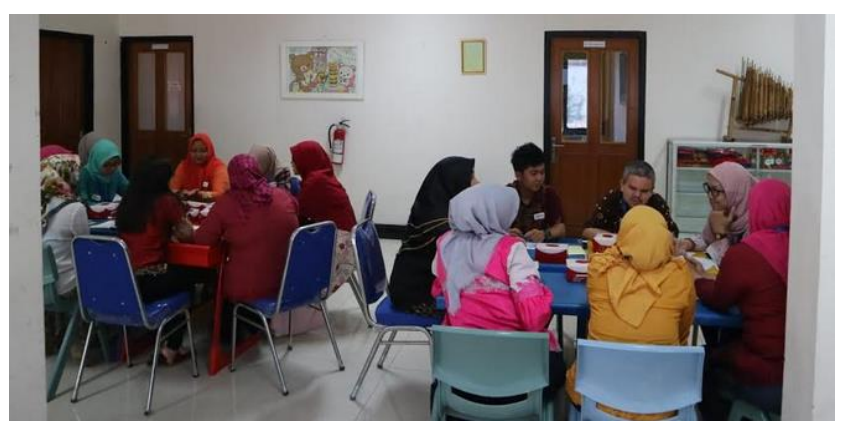

Gambar 1. Pelaksanaan Focus Group Discussion

Selanjutnya, pada tanggal 15 Maret 2019 dilaksanakan kegiatan pelatihan. Dalam sesi pelatihan, peserta terlebih dahulu dijelaskan mengenai pentingnya kegiatan bermain untuk meningkatkan kualitas hidup anak penderita kanker. Setelah itu, peserta diberikan penjelasan mengenai tata cara bermain dengan pendekatan theraplay. Dalam kegiatan pelatihan ini, peserta juga diberikan kesempatan mencoba beberapa aktivitas bermain dengan pendekatan theraplay.

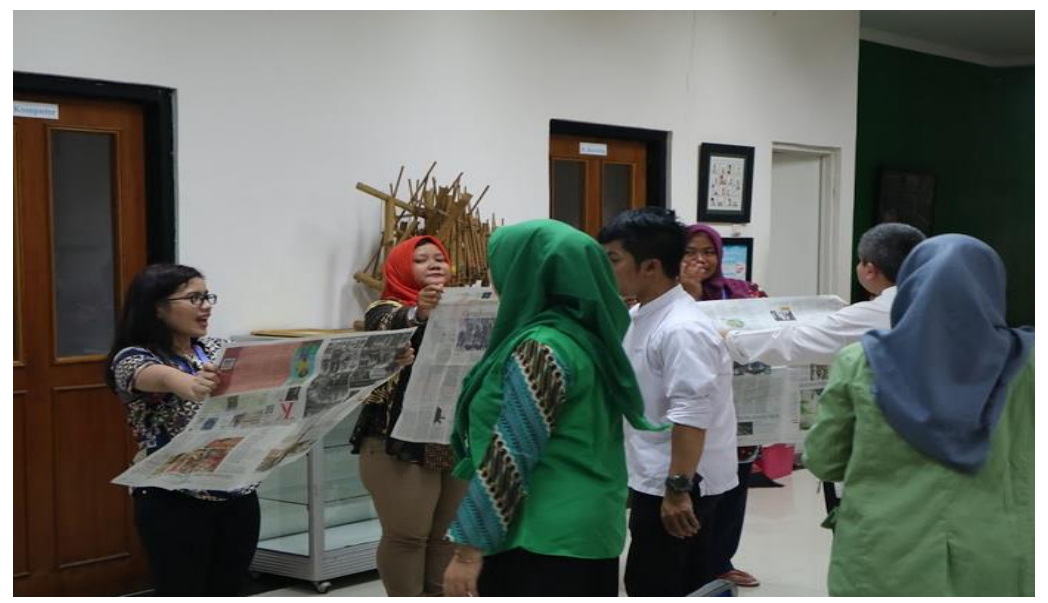

Gambar 2. Pelaksanaan Sesi Pelatihan

Berikutnya, pada tanggal 19 Maret 2019 dilaksanakan kegiatan follow up berupa observasi kegiatan bermain yang dilakukan peserta pada seting alami. Untuk melihat sejauh mana peserta dapat menerapkan apa yang sudah dipelajari dalam kegiatan bermain sehari-hari. Dalam observasi ini, observer dibekali checklist perilaku untuk melihat perilaku apa saja yang muncul sesuai dengan pendekatan theraplay. 


\section{Perbandingan Pre Test dan Post Test}

Berdasarkan analisis statistic Wilcoxon signed rank test, diketahui bahwa terdapat perbedaan yang signifikan dalam pengetahuan mengenai theraplay $(\mathrm{Z}=-3.236, \mathrm{p}<0.05)$ sebelum dan sesudah kegiatan pelatihan, dimana pengetahuan peserta setelah kegiatan pelatihan lebih tinggi secara signifikan dibandingkan sebelum pelatihan. Hal ini menandakan bahwa terdapat kegiatan pelatihan ini secara signifikan meningkatkan pengetahuan peserta pelatihan mengenai theraplay.

\section{Hasil Follow up}

Berdasarkan hasil observasi yang mengacu pada checklist perilaku, didapatkan hasil yang tampak dalam grafik sebagai berikut:

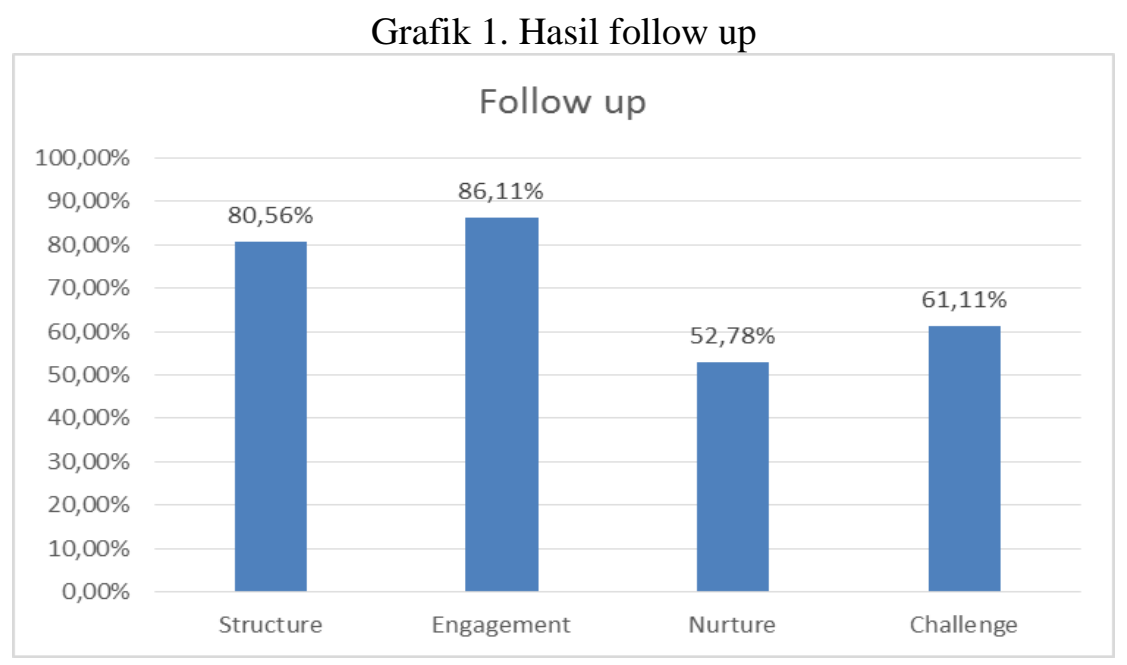

Dari grafik diatas, tampak bahwa perilaku yang mengindikasikan dimensi-dimensi dalam theraplay telah muncul sebesar 52,78\% hingga $86,11 \%$. Dimensi engagement merupakan dimensi dengan kemunculan perilaku terbesar, sementara dimensi nurture merupakan dimensi dengan kemunculan perilaku terkecil.

\section{Hasil Evaluasi Kegiatan}

Evaluasi kegiatan mengacu pada seberapa puas peserta terhadap aspek kompetensi pembicara, kejelasan materi yang diberikan, kesempatan berdiskusi, manfaat kegiatan, waktu pelaksanaan serta sarana dan prasarana. Dalam setiap aspek, peserta diminta untuk memberikan penilaian dalam rentang 1-4, dimana 1 menandakan bahwa mereka tidak puas dan 4 menandakan bahwa mereka sangat puas. Hasil pengolahan data dari lembar evaluasi dapat dilihat dalam grafik berikut:

\section{Grafik 2. Hasil Evaluasi Kegiatan}

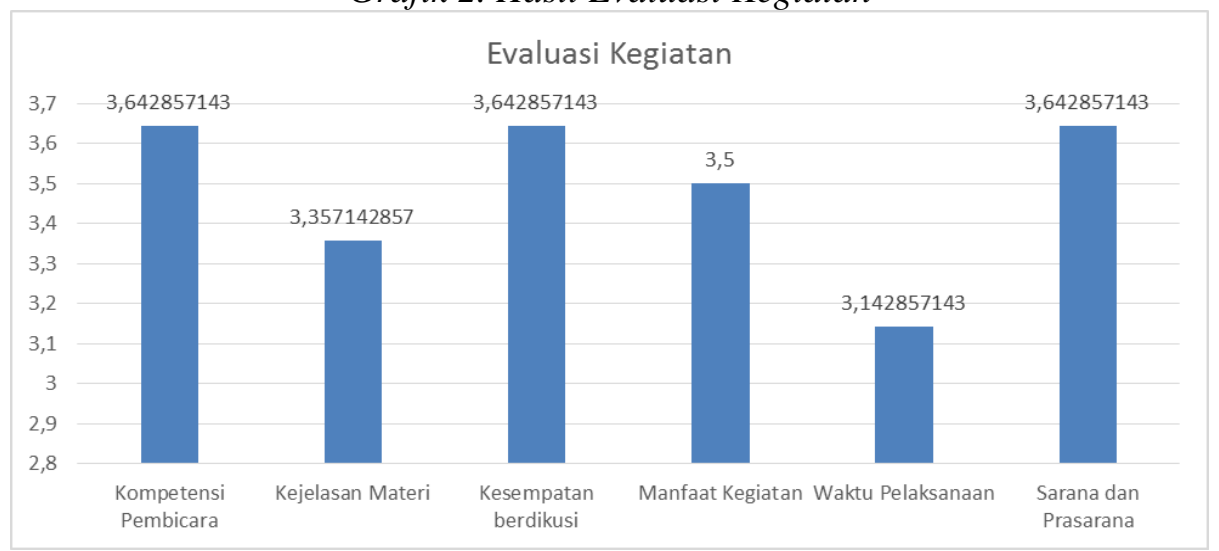

Dari grafik diatas terlihat bahwa peserta puas dengan seluruh aspek penilaian yang ada. Tingkat kepuasan tertinggi adalah pada aspek kompetensi pembicara, kesempatan berdiskusi dan 
sarana dan prasarana. Sementara itu, waktu pelaksaaan kegiatan menjadi aspek dengan tingkat kepuasan terendah jika dibandingkan dengan aspek lainnya. Hal ini dimungkinkan karena waktu pelaksanaan kegiatan yang dianggap kurang panjang oleh peserta.

\section{KESIMPULAN}

Berdasarkan evaluasi yang dilakukan, dapat disimpulkan bahwa pelatihan pendekatan theraplay untuk guru sekolahku terbukti dapat meningkatkan pengetahuan dan keterampilan para guru dalam bermain melalui pendekatan theraplay.

\section{SARAN}

Berdasarkan hasil follow up, diketahui bahwa dimensi nurture merupakan dimensi dengan kemunculan perilaku terendah dibandingkan dengan dimensi lainnya. Berdasarkan hal ini, sesi yang lebih dalam mengenai dimensi nurture dirasa diperlukan untuk meningkatkan keterampilan peserta dalam dimensi tersebut.

\section{UCAPAN TERIMA KASIH}

Penulis mengucapkan terima kasih kepada Yayasan YARSI yang telah memberi dukungan financial secara penuh terhadap kegiatan pengabdian kepada masyarakat ini. Penulis juga mengucapkan terimakasih kepada YKAKI karena telah bersedia menjadi mitra dalam kegiatan ini.

\section{DAFTAR PUSTAKA}

[1] American Cancer Society. Cancer Facts \& Figures 2015. Atlanta, GA: American Cancer Society; 2015

[2] Davidson, B., Satchi, N. S., \& Venkatesan, L. (2017). Effectiveness of Play Therapy upon Anxiety among Hospitalised. International Journal Of Advence Research, Volume 3 No. 5

[3] Wettig, H. H. G., Franke, U., \& Fjordbak, B. S. (2006). Evaluating the Effectiveness of theraplay. In C. E. Schaefer \& H. G. Kaduson (Eds.), Contemporary play therapy: Theory, research, and practice (pp. 103-135). New York, NY, US: Guilford press. 